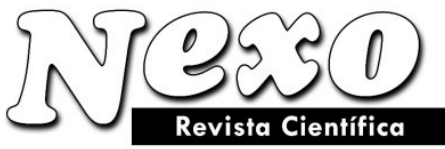

ISSN-E 1995-9516

Universidad Nacional de Ingeniería http://revistas.uni.edu.ni/index.php/Nexo http://dx.doi.org/10.5377/nexo.v30i2.5530

Vol. 30, No. 02, pp. 96-110/Diciembre 2017

(C) $($ ) $\Theta$

\title{
AISLAMIENTO E IDENTIFICACIÓN DE BACILLUS subtilis Y EVALUACIÓN DEL ANTAGONISMO IN VITRO FRENTE HONGOS FITOPATÓGENOS
}

\section{ISOLATION AND IDENTIFICATION OF BACILLUS subtilis AND EVALUATION OF ANTAGONISM IN VITRO AGAINST PHYTOPATHOGENIC FUNGI}

\author{
J.M. Méndez-Úbeda ${ }^{1}$, M.S. Flores Hernández ${ }^{2}$, L.A Páramo-Aguilera ${ }^{3, *}$ \\ ${ }^{1}$ Universidad Nacional de Ingeniería. Facultad de Tecnología de la Construcción (FTC), Departamento de \\ Ingeniería Agrícola. Managua, Nicaragua. \\ ${ }^{2}$ Universidad Nacional de Ingeniería. Facultad de Tecnología de la Construcción (FTC). Managua, \\ Nicaragua. \\ ${ }^{3}$ Universidad Nacional de Ingeniería. Programa de Investigación, Estudios Nacionales y Servicios del \\ Ambiente (PIENSA). Managua, Nicaragua. \\ *leandro.paramo@piensa.uni.edu.ni; lparamo2014@gmail.com
}

(recibido/received: 05-Noviembre-2017; aceptado/accepted: 27-Noviembre-2017)

\section{RESUMEN}

Los microorganismos fitopatógenos son una amenaza importante para la producción de alimentos y su control mediante el uso de microorganismos antagonistas es una práctica mundial, lo que ha llevado a la investigación y búsqueda de nuevos aislamientos que sean efectivos en el control biológico. En esta investigación se llevó a cabo el aislamiento e identificación de bacterias a partir de bioinsumos producido artesanalmente en Nicaragua y se evaluó in vitro su antagonismo frente a hongos fitopatógenos de interés agrícola. Se realizó la caracterización morfológica de 14 aislados bacterianos y confirmación por secuenciación del gen ADNr 16S; posteriormente se evaluó el potencial antagónico mediante confrontación dual frente a los hongos identificados como Fusarium equiseti, Fusarium sp. y Alternaría alternata. Como resultado se encontraron 6 cepas con efecto inhibitorio, sobresaliendo Bacillus subtilis cepa F con los mejores porcentajes de inhibición del crecimiento de los fitopatógenos evaluados en un rango de 50-100\%. Otros resultados de interés fueron obtenidos mediante la identificación de Bacillus megaterium y la utilización de Rhizobium $s p$, este último inhibió entre 50-90\% el crecimiento de los hongos, lo cual sugiere considerar su aplicación no solo como bioestimulante, sino también como bioprotector al inhibir de crecimiento de ciertos fitopatógenos.

Palabras clave: Bacteria, control biológico, microorganismo, bioinsumo, antagonismo.

\begin{abstract}
Plant pathogens microorganisms are an important threat to food production and their control through the use of antagonistic microorganisms is a world practice, which has led to research and search for new isolates that are effective in biological control. In this investigation the isolation and identification of bacterium from
\end{abstract}


bioinsumos produced in Nicaragua was carried out and its antagonism against phytopathogenic fungi of agricultural interest was evaluated in vitro. Morphological characterization of 14 bacterial isolated and confirmation by sequencing of the $16 \mathrm{~S}$ rDNA gene; later the antagonistic potential was evaluated by dual confrontation against the fungi identified as Fusarium equiseti, Fusarium sp. and Alternaria alternata. As a result, 6 inhibitory strains were found, with Bacillus subtilis strain F showing the best percentages of inhibition of the growth of phytopathogens evaluated in a range of 50-100\%. Other interesting results were obtained by the identification of Bacillus megaterium and the use of Rhizobium sp, the latter inhibited between $50-90 \%$ the growth of fungi, which suggests to consider its application not only as a biostimulant, but also as a bioprotector when inhibiting of growth of certain phytopathogens.

Keywords: Bacterium, biological control, microorganism, bioinsumo, antagonism.

\section{INTRODUCCIÓN}

La agricultura bajo el modelo de producción convencional resulta cada día menos sostenible, afectando la parte ambiental, económica y social de las zonas y regiones donde se practica. El uso indiscriminado de plaguicidas y fertilizantes químicos, sumado a la labranza inadecuada y la expansión de la frontera agrícola, ha generado desgaste en los ecosistemas (Barquero et al. 2007). En el caso de la aplicación sistemática de productos químicos en la agricultura implica algunas dificultades como el resurgimiento de plagas primarias y secundarias, el desarrollo de resistencia genética, la contaminación del medio ambiente y afectaciones a la salud humana. Muchos de estos productos provocan daños irreparables sobre el sistema nervioso central, y otros están clasificados como carcinogénicos (Reinoso et al., 2006).

La utilización de microorganismos en el control biológico de patógenos causantes de enfermedades en los cultivos, constituye una alternativa eficiente y ecológica que contribuye al desarrollo de una agricultura sostenible, ya que disminuye los efectos inherentes al uso de plaguicidas y productos químicos (RuizSánchez et al., 2014). Algunas investigaciones se han enfocado en la búsqueda de microorganismos nativos que actúen bajo las condiciones ambientales de cada región y puedan usarse para restablecer las interacciones de la microbiota del suelo, al punto que sean empleados como biofertilizantes y/o biocontroladores (bioinsumos), que mitiguen el impacto ambiental de los agroquímicos y reduzcan los costos de producción (Orberá et al., 2014). De acuerdo con (Compant et al., 2005) el desarrollo de estos bioproductos para el control de enfermedades en las plantas, se encaminan a aspectos como la preservación ecológica de la interacción planta-microrganismo, las estrategias de aplicación de los inoculantes, el aislamiento de cepas nuevas y el descubrimiento de mecanismos de acción novedosos. Se enfatiza, además, en el uso de los agentes de biocontrol como parte de los programas de tratamiento integral de enfermedades y de la calidad de los suelos.

Se ha demostrado que las bacterias del género Bacillus presentan un gran potencial como antagonistas, principalmente por la gran cantidad de enzimas líticas, antibióticos y otras sustancias con actividad biocida, que son capaces de producir efectos de control sobre varias especies de organismos fitopatógenos (Sosa $e t$ al., 2005; Castillo-Reyes et al., 2015). El efecto biocontrolador de Bacillus spp. frente a Fusarium spp. bajo condiciones de invernadero en el cultivo de Romero (Rosmarinus officinalis L) fue evaluado por (Corrales et al., 2011), obteniendo que todos los aislamientos de Bacillus spp., presentaron efecto biocontrolador sobre Fusarium spp. en romero al disminuir la severidad de la marchitez vascular en las plántulas por debajo del $50 \%$, lo que valida los resultados obtenidos en las pruebas in vitro y lo señalado en la literatura acerca de estas bacterias.

Esta investigación estuvo orientada al aislamiento e identificación morfológica y molecular de microorganismos nativos de Nicaragua partiendo de bioinsumos artesanales (4 muestras), en la búsqueda de bacterias (B. subtilis) antagonistas de hongos fitopatógenos pertenecientes a los géneros Fusarium y

Nexo Revista Científica / Vol. 30, No. 02, pp. 96-110 / Diciembre 2017 


\section{J.M. Méndez-Úbeda et al.}

Alternaría; para lo cual se realizaron ensayos de antagonismo in vitro, a través de la confrontación dual de las bacterias con potencial antagónico de los hongos fitopatógenos evaluados.

\section{MATERIALES Y METODOS}

2.1 Aislamiento de microorganismos a partir de bioinsumos artesanales

El aislamiento se llevó a cabo por medio de la suspensión aséptica de $1 \mathrm{~g}$ de muestra de bioinsumos en 5 $\mathrm{mL}$ de agua destilada estéril, con agitación vigorosa en vortex por $20 \mathrm{~s}$ (Solución madre). A partir de la solución madre antes preparada, se tomó $0.1 \mathrm{~mL}$ que se inoculó y esparció con espátula de Drigalsky en placas Petri con medios Agar Papa Dextrosa (PDA), Agar Plate Count (PCA) y Agar Nutritivo (AN) e incubadas a $35^{\circ} \mathrm{C}$ durante $24 \mathrm{~h}$ para bacterias y 5 días para hongos, con el propósito de aislar la mayor cantidad posible de microorganismos cultivables (Benítez et al., 2007; Badía et al., 2011; Cuervo, 2010; Reinoso et al., 2006). Transcurridos los tiempos antes indicados, las placas fueron observadas al contador de colonias con lupa de aumento y se diferenciaron por color y forma las diferentes colonias bacterianas y de hongos filamentosos. Las colonias bacterianas fueron llevadas a placas Petri con medio AN, por agotamiento para su purificación y las correspondientes a hongos filamentosos fueron llevadas a placas con medio PDA. Finalmente se observaron las placas al estereomicroscopio para definir la uniformidad visual a un mismo tipo de colonia (Badía et al., 2011; Cuervo, 2010).

\subsection{Aproximación a la identificación morfológica de los aislados}

Se tomó una muestra representativa de cada aislado bacteriano para realizarles tinción Gram siguiendo el procedimiento descrito por (Moreno \& Albarracín 2012) y observarlas al microscopio (OLYMPUS) con el objetivo 100X y aceite de inmersión; esto para determinar si las bacterias asiladas eran Gram positivas o Gram negativas, así como la forma de las colonias si eran cocales, bacilares, esféricas, etc. En el caso de los hongos filamentosos se realizó la observación de esporas al microscopio con objetivo de 50X, utilizando la técnica de impresión con cinta adhesiva transparente; para los hongos levaduriformes se realizó tinción simple con cristal violeta y observación con objetivo 40X (Moreno \& Albarracín, 2012).

\subsection{Identificación molecular de los microorganismos}

Se llevó a cabo a través de la secuenciación parcial del gen ADN ribosomal 16S para bacterias e ITS 1 (Internal Transcribed Space) para hongos (Álvarez et al., 2013). El servicio de secuenciación de ADN se realizó en el Centro de Biología Molecular (CBM) de la Universidad Centroamericana (UCA). Una vez obtenidas las secuencias, se corrigieron utilizando el software Bioedit v7.0.9, posteriormente se obtuvieron del GenBank del National Center for Biotechnology Information (NCBI) secuencias de las regiones estudiadas de hongos y bacterias relacionadas taxonómicamente con los microorganismos, usando la herramienta BLAST (Basic Local Aligment Search Tool) para comparar secuencias altamente similares (Castillo-Reyes et al., 2015). Se realizó un alineamiento múltiple con cinco secuencias elegidas para cada secuencia en estudio, utilizando la aplicación Clustal W Multiple alignment versión 1.4 incluida en el menú Accesory Application del programa Bioedit v7.0.9 y se utilizaron los parámetros por defecto. Los árboles filogenéticos se construyeron usando el programa MEGA 7.0.14 usando el método Neighbor-Joining Tree, evaluando la confiabilidad haciendo bootstrapping de 1000 repeticiones (Castillo-Reyes et al., 2015; Tamura et al., 2011 citado por Rodríguez C., 2013 y Álvarez et al., 2013).

Como material biológico para la confrontación in vitro, se utilizaron las cepas X5-9E2, X2-10(2)2 y X59CD2 suministradas por el Laboratorio de Microbiología de la Facultad de Ciencia Animal de la Universidad Nacional Agraria (UNA), aisladas de ciego de pollo (intestino) e identificadas a través de pruebas bioquímicas dentro del género Bacillus, utilizadas como controles positivos en esta investigación; las cepas F9 y F15 aisladas de maní (Arachis hypogaea) pertenecientes a la colección de aislados del

Nexo Revista Científica / Vol. 30, No. 02, pp. 96-110 / Diciembre 2017 
Laboratorio de Fitopatología de la Facultad de Agroecología de la Universidad Nacional Autónoma de Nicaragua (UNAN-León); M121 y M311 aisladas de papa (Solanum tuberosum L) suministradas por el Programa Institucional Agropecuario y Agroindustrial de la Universidad Nacional de Ingeniería (UNI). Como material de trabajo se utilizaron muestras de bioinsumos artesanales (disponibles comercialmente a nivel local) colectados en dos zonas del país (norte y occidente).

\subsection{Preselección de aislados como potenciales antagonistas}

La metodología utilizada para este ensayo fue la empleada por (Benítez et al., 2007), con algunas modificaciones. Se inocularon dos aislados bacterianos distintos (Previo a su identificación) en placas Petri con PDA haciendo dos líneas paralelas, cada una a $1 \mathrm{~cm}$ de distancia del borde de la placa Petri (Figura 1). Seguidamente, se colocó un explante del hongo fitopatógeno en el centro de la placa y se incubó a temperatura ambiente $\left(28^{\circ} \mathrm{C}\right)$ hasta observar algún efecto sobre el crecimiento del fitopatógeno. Esto permitió realizar un screen grueso de todos los aislados bacterianos con algún potencial antagónico contra los patógenos de interés.

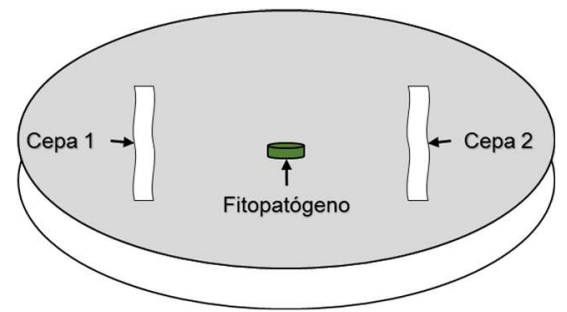

Figura 1. Colocación de los microorganismos a utilizarse en la preselección.

2.5 Evaluación del efecto antagónico haciendo énfasis en la búsqueda de B. subtilis

Se determinó por medio de la técnica de confrontación dual entre los antagonistas y los fitopatógenos (Tejera et al., 2012; Badía et al., 2011; Corrales et al., 2011). En placa Petri con medio PDA, las bacterias seleccionadas (en la etapa anterior) se sembraron por estrías en toda la superficie del medio, se incubaron por 24 horas a $35^{\circ} \mathrm{C}$. Posteriormente se colocó en el centro un disco de $0.5 \mathrm{~cm}$ de diámetro del fitopatógeno con 7 días de crecimiento previo y se incubó a $28^{\circ} \mathrm{C}$, hasta que el testigo con el hongo y sin bacteria llenara la placa Petri. Se realizaron tres repeticiones por tratamiento. La variable medida fue el diámetro de crecimiento radial del hongo fitopatógeno en presencia del antagonista bacteriano. Como control negativo o testigo se utilizaron placas donde se encontraban únicamente los hongos evaluados; con las mediciones obtenidas se determinó el porcentaje de inhibición, utilizando la Ecuación de (Badía et al., 2011).

$$
\% \text { Inhibición }=\left(\frac{\text { D.C.C }- \text { D.C.P }}{\text { D.C.C }}\right) * 100
$$

Dónde:

D.C.C: Diámetro de la colonia control $(\mathrm{cm})$.

D.C.P: Diámetro de la colonia problema (hongo en presencia de los antagonistas) $(\mathrm{cm})$.

\section{RESULTADOS Y DISCUSIÓN}

\subsection{Aislamiento de microorganismos}

En esta investigación se utilizaron métodos clásicos o tradicionales de cultivos y se logró obtener aislados de la microbiota cultivable presente en las muestras analizadas, sin embargo, esto no representa a todos los microorganismos que se encuentran en ellas y está limitado por los medios que se utilizaron. Utilizando métodos clásicos o tradicionales de cultivos, se obtuvieron 30 aislados diferentes de colonias de 
microorganismos en las distintas muestras de bioinsumos entre bacterias y hongos; de estos, 23 fueron bacterianos, 6 de hongos filamentosos y 1 de hongo levaduriforme como los mostrados en la Figura 2 BIBIII.

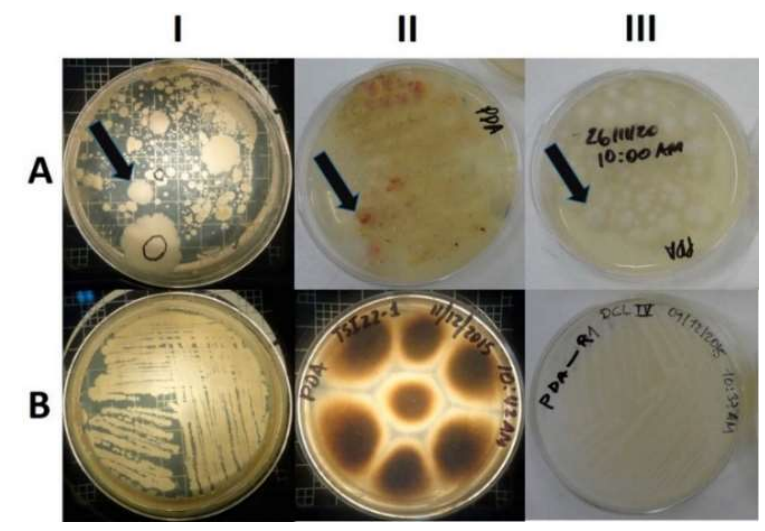

Figura 2. Aislamiento de microorganismos cultivables presentes en las muestras de los bioinsumos. AI-AIII: Placas Petri con cultivo mixto inicial. Las flechas señalan colonias seleccionadas para aislarse de una bacteria, un hongo filamentoso y uno levaduriforme, que se muestran aislados en BI, BII y BIII respectivamente.

(Cuervo 2010) aisló microorganismos de dos biofertilizantes comerciales (uno de producción artesanal en medio líquido que especifica que contiene un coctel de microorganismos y el otro en medio sólido en polvo que contiene un Bacillus sp.) obteniendo solamente 3 aislados bacterianos que se identificaron mediante pruebas bioquímicas como: Bacillus subtilis en medio sólido, Bacillus firmus y Bacillus sphaericus en medio líquido. Estos resultados difieren con los obtenidos en este trabajo, en el que se obtuvo una gran cantidad de aislados microbianos, lo cual pueda deberse al bajo nivel tecnológico con el que se producen los bioinsumos utilizados actualmente en Nicaragua que no poseen cepas selectas según se indica en el documento (Estado de la Agricultura Orgánica en Nicaragua: Propuesta para su Fomento y Desarrollo, 2009). Por el contrario los boinsumos utilizados en este estudio, están compuestas por una cantidad de microorganismos de los cuales no se conoce su identidad y su función dentro del producto (si son o no benéficos). No obstante, esto nos permitió obtener un mayor número de microorganismos aumentando la posibilidad de encontrar alguna especie nativa de Bacillus subtilis.

\subsection{Identificación morfológica de los aislados bacterianos}

A los aislados bacterianos puros obtenidos en este trabajo, después de incubarlos por 24 horas en medio AN a $35^{\circ} \mathrm{C}$, se les sometió a pruebas de tinción de Gram. Se observó la forma y tamaño de las células, la forma de colonia, así como su clasificación en Gram positivas o Gram Negativas. De acuerdo a la forma de la célula y el resultado de la tinción, 22 de los aislados eran de forma bacilar de distintos tamaños: 12 Gram positivos (entre paréntesis se muestra la ubicación en la Figura 3 del Gram correspondiente a cada bacteria): DCL1-2 (AI b), DCL2-1 (CI b), DCL2-411 (DI b), DCL3-3 (EI b), DCL4-31 (GI b), LS5-11 (FII b), LS521 (GII b), LS6-11 (HII b), LS6-211 (AIII b), TS10-111 (CIII b), TS11-3 (DIII b) y TS13-1111; 3 Gram variables: DCL3-4 (FI b), LS5-1 (EII b) y TS11-31 (EIII b); 7 Gram negativos: DCL1-11 (BI b), DCL1221 (HI b), DCL12-1111 (AII b), LL8-221 (CII b), LL9-21 (DII b), LS7-211 (BIII b) y TS13-2111 (GIII b); y 1 de forma cocal Gram positivo: LL8-111 (BII b). 


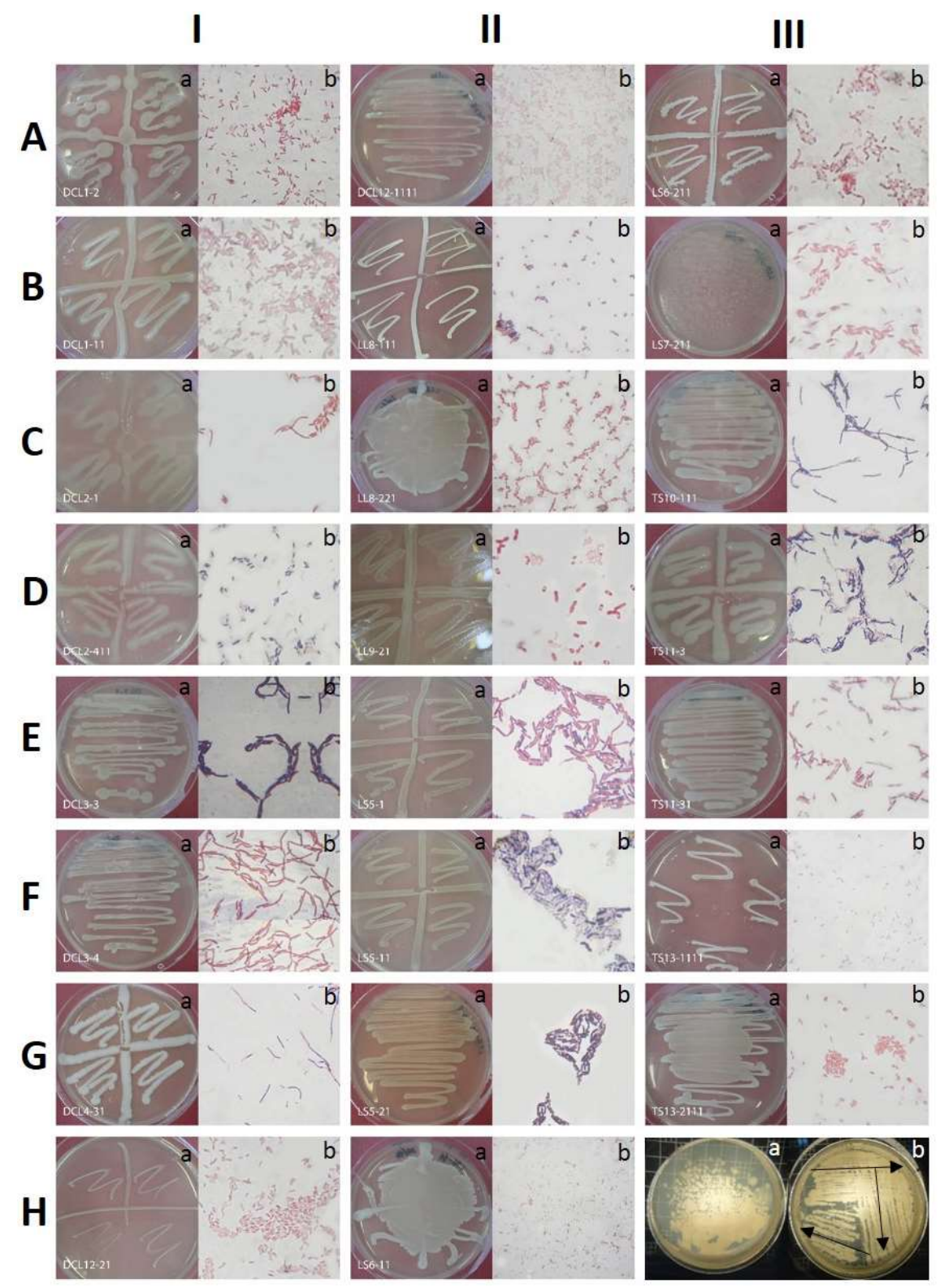

Figura 3. Morfología en placa y tinción de Gram de los aislados bacterianos. AI-HI, AII: Muestra 4; BII-DII: Muestra 3; EII-HII, AIII, BIII: Muestra 2; CIII-GIII: Muestra 1; HIII a: Cultivo mixto obtenido en la primera inoculación y HIII b: agotamiento por estrías.

En la Figura 3 se puede observar que de las 23 bacterias aisladas se obtuvieron 12 bacterias de forma bacilar que resultaron ser Gram positivas (DCL1-2, DCL2-1, DCL2-411, DCL3-3, DCL4-31, LS5-11, LS5-21, LS6-11, LS6-211, TS10-111, TS11-3, TS13-1111), características del género Bacillus. Esto concuerda con los resultados de Badía et al. (2011) donde obtuvieron 13 aislados con estas características. De acuerdo con (Tejera-Hernández et al., 2011) la presencia de endosporas bacterianas que constituyen una estructura de resistencia que puede permanecer viable durante una gran cantidad de tiempo hasta que las condiciones se tornen favorables para el desarrollo de la forma vegetativa, justificaría la gran cantidad de especies del genero Bacillus que se encuentren en una gran variedad de hábitats. (Sosa et al., 2005) refuerzan esta afirmación explicando que las especies de Bacillus son ubicuas en la naturaleza, encontrándose en mayor proporción en los suelos como microorganismos saprófitos, resultando de gran utilidad usar muestras de suelo como fuente de inóculo. Para el caso de los bioinsumos utilizados, uno de sus componentes son suelos 


\section{J.M. Méndez-Úbeda et al.}

tomados de distintas zonas, lo cual explicaría la cantidad de aislados bacilares Gram positivos obtenidos de las muestras.

\subsection{Identificación morfológica de los fitopatógenos utilizados en pruebas de antagonismo}

En cuanto a los fitopatógenos suministrados como Fusarium y el aislado de Alternaría, su identificación morfológica se llevó a cabo mediante la observación de las características en placa y al microscopio de luz y comparación con la literatura. Las formas de las esporas observadas se muestran en la Figura 4, así como su morfología en medio PDA.

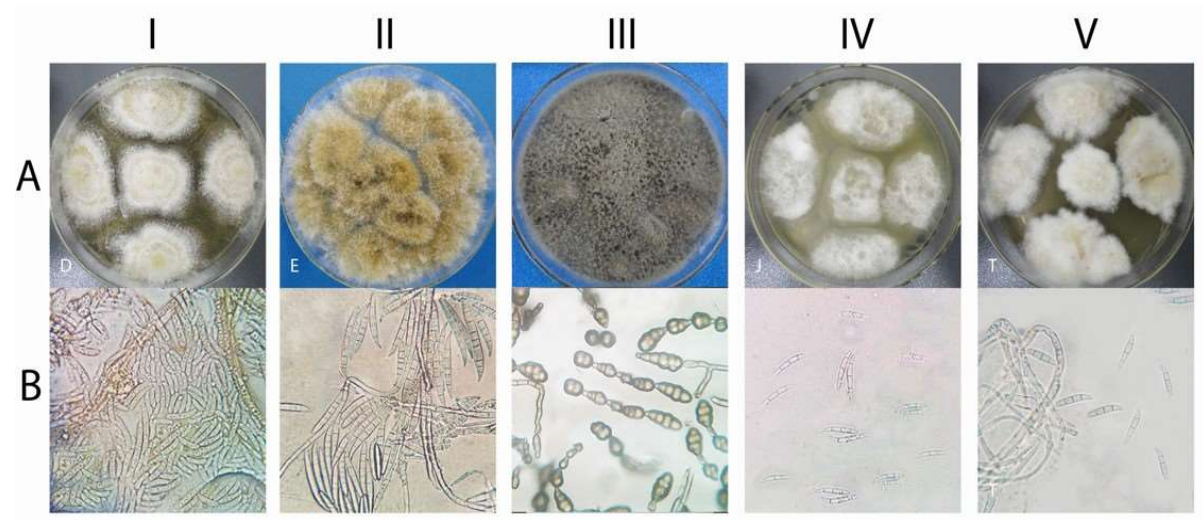

Figura 4. Hongos fitopatógenos utilizados en pruebas de antagonismo. AI, AIV: Fusarium M1-2-1 (D) y M3-1-1 (J) aislados de papa; AII, AV: Fusarium F15 (E) y F9 (T) aislados de maní; AIII: Alternaría M5-62N (I) aislado de papa.

Las esporas de los fitopatógenos observadas (Figura 4: BI-BV) concuerdan con las que se muestran en la literatura consultada (Carrillo, 2003; Kikot, 2012), correspondiente a los géneros Alternaría cepa M5-62N (I) y a Fusarium cepas M1-2-1 (D), M3-1-1 (J), F15 (E) y F9 (T). En el caso de Alternaría el micelio era de color gris verdoso, tornándose más oscuro al envejecer el cultivo y sus esporas de color pardo con septos transversales, estas características se pueden observar en la Figura 4 AIII y BIII. Mientras que Fusarium mostraba micelio abundante blanco, tornándose amarillento o crema en el hongo ya esporulado; sus esporas con forma de media luna o canoa característica que permite diferenciar este género con facilidad como puede observarse en la Figura 4 BI, BII, BIV y BV.

\subsection{Identificación molecular de los microorganismos utilizados en este estudio}

Se escogieron 15 bacterias para la identificación molecular, de las cuales 12 pertenecían a las aisladas de las muestras de bioinsumos ( 9 bacilos Gram positivos entre los que podría encontrarse Bacillus subtilis, 2 bacilos Gram negativos y 1 coco Gram positivo), seleccionados para conocer la diversidad de géneros y especies que conviven en estos bioinsumos; las 3 bacterias restantes fueron suministradas por el Laboratorio de Microbiología de la Facultad de Ciencia Animal de la Universidad Nacional Agraria (UNA), aisladas de ciego de pollo (intestino) e identificadas a través de pruebas bioquímicas dentro del género Bacillus y que sirvieron como controles positivos en esta investigación. De los 15 aislados de bacterias seleccionados, 10 se lograron identificar a nivel de especie; 4 a nivel de género y una de las bacterias no se obtuvieron buenos resultados en la secuenciación. De un total de 14 bacterias identificadas vía molecular, 10 pertenecen al género Bacillus, y de ellas 2 cepas corresponden a Bacillus subtilis DCL4-31 (F) y LS6-11 (G) (Tabla 1). 


\section{J.M. Méndez-Úbeda et al.}

Tabla 1. Identificación de bacterias mediante análisis filogenético (árbol filogenético no incluido). En la tabla se muestra el código de la secuencia y el código del microorganismo, además de la muestra de donde se aisló, puntuación e identidad máxima con el vecino cercano y la identidad final de la bacteria.

\begin{tabular}{|c|c|c|c|c|c|c|}
\hline \multicolumn{7}{|c|}{ Bacterias } \\
\hline $\begin{array}{l}\text { Código } \\
\text { secuencia }\end{array}$ & $\begin{array}{l}\text { Código } \\
\text { microorganismo }\end{array}$ & $\begin{array}{l}\text { Procedencia } \\
\text { de la muestra }\end{array}$ & $\begin{array}{l}\text { Vecino cercano } \\
\text { (Número acceso) }\end{array}$ & $\begin{array}{l}\text { Máx } \\
\text { punt. }\end{array}$ & $\begin{array}{l}\text { Ident. } \\
\text { máx. (\%) }\end{array}$ & Identidad final \\
\hline A & DCL1-2 & Bioinsumos & $\begin{array}{l}\text { Lysinibacillus } \quad s p . \\
\text { (KU372128) }\end{array}$ & 358 & 100 & $\begin{array}{l}\text { Lysinibacillus sp. } \\
\text { (MF680178) }\end{array}$ \\
\hline B & LS5-11 & Bioinsumos & $\begin{array}{l}\text { Bacillus megaterium } \\
\text { (KR063189) }\end{array}$ & 1105 & 99 & $\begin{array}{l}\text { Bacillus megaterium } \\
\text { (MF680179) }\end{array}$ \\
\hline C & TS11-3 & Bioinsumos & $\begin{array}{l}\text { Bacillus } \\
\text { (KM114626) }\end{array}$ & 1478 & 99 & $\begin{array}{l}\text { Bacillus sp. } \\
\text { (MF680180) }\end{array}$ \\
\hline $\mathbf{F}$ & DCL4-31 & Bioinsumos & $\begin{array}{l}\text { Bacillus subtilis } \\
\text { (KX454091) }\end{array}$ & 1022 & 99 & $\begin{array}{l}\text { Bacillus subtilis } \\
\text { (MF680181) }\end{array}$ \\
\hline G & LS6-11 & Bioinsumos & $\begin{array}{l}\text { Bacillus subtilis } \\
\text { (KU764381) }\end{array}$ & 1057 & 99 & $\begin{array}{l}\text { Bacillus subtilis } \\
\text { (MF680182) }\end{array}$ \\
\hline H & DCL2-411 & Bioinsumos & $\begin{array}{ll}\begin{array}{l}\text { Bacillus } \\
(\text { KC713922) }\end{array} & \text { flexus }\end{array}$ & 1114 & 100 & $\begin{array}{l}\text { Bacillus flexus } \\
\text { (MF680183) }\end{array}$ \\
\hline $\mathbf{L}$ & DCL12-21 & Bioinsumos & $\begin{array}{l}\text { Agrobacterium } \\
\text { tumefaciens } \\
\text { (KM894180) }\end{array}$ & 2490 & 99 & $\begin{array}{l}\text { Agrobacterium } \\
\text { tumefaciens } \\
\text { (MF680185) }\end{array}$ \\
\hline $\mathbf{M}$ & LL8-111 & Bioinsumos & $\begin{array}{l}\text { Staphylococcus } \\
\text { succinus } \\
\text { (KF254629) }\end{array}$ & 2601 & 100 & $\begin{array}{l}\text { Staphylococcus } \\
\text { succinus } \\
\text { (MF680186) }\end{array}$ \\
\hline $\mathbf{N}$ & TS13-1111 & Bioinsumos & $\begin{array}{l}\text { Bacillus pumilus } \\
\text { (KT371465) }\end{array}$ & 2362 & 98 & $\begin{array}{l}\text { Bacillus pumilus } \\
\text { (MF680187) }\end{array}$ \\
\hline $\mathbf{O}$ & X5-9E2 & $\begin{array}{l}\text { Ciego de } \\
\text { pollo }\end{array}$ & $\begin{array}{ll}\begin{array}{l}\text { Bacillus } \\
\text { (KF641830) }\end{array} & \text { cereus } \\
\end{array}$ & 1083 & 99 & $\begin{array}{l}\text { Bacillus cereus } \\
\text { (MF680188) }\end{array}$ \\
\hline $\mathbf{P}$ & LS6-211 & Bioinsumos & $\begin{array}{l}\text { Bacillus } \\
\text { (KX710327) }\end{array}$ & 1014 & 99 & $\begin{array}{l}\text { Bacillus sp. } \\
\text { (MF680189) }\end{array}$ \\
\hline $\mathbf{Q}$ & DCL12-11 & Bioinsumos & $\begin{array}{l}\text { Rhizobium } \\
\text { (KX350124) }\end{array}$ & 1051 & 100 & $\begin{array}{l}\text { Rhizobium sp. } \\
\text { (MF680190) }\end{array}$ \\
\hline $\mathbf{R}$ & $\mathrm{X} 2-10(2) 2$ & $\begin{array}{l}\text { Ciego } \quad \text { de } \\
\text { pollo }\end{array}$ & $\begin{array}{ll}\begin{array}{l}\text { Bacillus } \\
\text { (KF641834) }\end{array} & \text { cereus }\end{array}$ & 1555 & 98 & $\begin{array}{l}\text { Bacillus cereus } \\
\text { (MF680184) }\end{array}$ \\
\hline $\mathbf{S}$ & $\mathrm{X} 5-9 \mathrm{CD} 2$ & $\begin{array}{l}\text { Ciego } \\
\text { pollo }\end{array}$ & $\begin{array}{l}\begin{array}{l}\text { Bacillus } \\
(\text { HQ694049) }\end{array} \\
\text { cereus }\end{array}$ & 1194 & 98 & Bacillus cereus \\
\hline
\end{tabular}

Aparte de B. subtilis, que era la especie que se pretendía encontrar por su potencial en el control biológico, se encontraron otras del genero Bacillus como B. megaterium reportado con capacidad de solubilizar fosfatos (Tejera-Hernández et al., 2011), B. flexus usado en tratamiento de aguas residuales alcalinas (Chen et al., 2013), B. pumilus conocido por su capacidad de producir fitohormonas (Pérez, 2012) у B. cereus reportado como antagonista de Phytophthora megasperma por (Handelsman et al. 1990) pero también como patógeno humano. Además, se encontraron otros géneros, tales como: Lysinibacillus, Agrobacterium, Sthaphylococcus y Rhizobium; este último de gran importancia en la agricultura, conocido por los nódulos que forma en simbiosis con plantas para la fijación del nitrógeno.

Los hongos fitopatógenos identificados según su tipo de espora: Alternaria M5-62N (I) y como Fusarium M1-2-1 (D), M3-1-1 (J), F15 (E) y F9 (T) se enviaron a secuenciar para identificarlos a nivel de especie. En Nicaragua de acuerdo a la IV versión de la Lista de Plagas reportadas publicada por el Instituto de Protección y Sanidad Agropecuaria (IPSA) en 2016, estos géneros afectan a la mayoría de los cultivos de interés (maíz, frijol, sorgo, soya, arroz, café, cacao, caña de azúcar, cítricos, melón, sandía, plátano, entre otros) causando pudrición o marchitez vascular en el caso de Fusarium y manchas foliares en el caso de Alternaría. Para verificar los resultados de la identificación morfológica de acuerdo al tipo de espora de los hongos 
fitopatógenos, se identificaron molecularmente a través de la secuenciación de la región ITS1 (Internal Transcribed Space) del ADNr. La Tabla 2 resume los resultados obtenidos en el análisis filogenético y la identificación de los hongos fitopatógenos.

Tabla 2. Identificación vía molecular de hongos fitopatógenos (árbol filogenético no incluido). En la tabla se muestra el código de la secuencia y el código del microorganismo, el cultivo a partir del cual se aisló, departamento de procedencia, puntuación e identidad máxima con el vecino más cercano y la identidad final del hongo.

\begin{tabular}{|c|c|c|c|c|c|c|c|}
\hline \multicolumn{8}{|c|}{ Hongos fitopatógenos } \\
\hline $\begin{array}{c}\text { Código } \\
\text { secuencia }\end{array}$ & $\begin{array}{l}\text { Código } \\
\text { microorganismo }\end{array}$ & $\begin{array}{l}\text { Aislado/ } \\
\text { cultivo }\end{array}$ & Procedencia & $\begin{array}{l}\text { Vecino cercano } \\
\text { (Número } \\
\text { acceso) }\end{array}$ & $\begin{array}{l}\text { Máx. } \\
\text { punt. }\end{array}$ & $\begin{array}{l}\text { Ident. } \\
\text { Máx. } \\
(\%)\end{array}$ & Identidad final \\
\hline D & M1-2-1 & Papa & Jinotega & $\begin{array}{l}\begin{array}{l}\text { Fusarium } \\
\text { (FJ827615) }\end{array} \\
\text { (Fp. }\end{array}$ & 974 & 99 & $\begin{array}{l}\text { Fusarium } s p . \\
\text { (MF817196) }\end{array}$ \\
\hline $\mathbf{E}$ & F15 & Maní & León & $\begin{array}{l}\text { Fusarium } s p . \\
(\text { KU377496) }\end{array}$ & 900 & 99 & $\begin{array}{l}\text { Fusarium sp. } \\
\text { (MF817197) }\end{array}$ \\
\hline $\mathbf{I}$ & M5-62N & Papa & Jinotega & $\begin{array}{l}\text { Alternaría } \\
\text { alternata } \\
\text { (KX179488) }\end{array}$ & 837 & 99 & $\begin{array}{l}\text { Alternaría } \\
\text { alternata } \\
\text { (MF817198) }\end{array}$ \\
\hline $\mathbf{J}$ & M3-1-1 & Papa & Jinotega & $\begin{array}{l}\text { Fusarium } \\
\text { equiseti } \\
\text { (KC311517) }\end{array}$ & 1956 & 99 & $\begin{array}{l}\text { Fusarium equiseti } \\
\text { (MF817199) }\end{array}$ \\
\hline $\mathbf{T}$ & F9 & Maní & León & $\begin{array}{l}\text { Fusarium } \\
\text { equiseti } \\
\text { (KU377992) }\end{array}$ & 876 & 100 & $\begin{array}{l}\text { Fusarium equiseti } \\
\text { (MF817200) }\end{array}$ \\
\hline
\end{tabular}

Los géneros Alternaría y Fusarium que se sugirieron a través de la observación de esporas concuerdan con los obtenidos en la identificación vía molecular con porcentajes de identidad entre el 99 y $100 \%$ con secuencias contenidas en el GenBank. Del total de 5 hongos fitopatógenos identificados vía molecular, 3 lograron ser identificados a nivel de especie M5-62N (I) como Alternaría alternata, M3-1-1 (J) y F9 (T) como Fusarium equiseti. Las cepas M1-2-1 (D) y F15 (E) se identificaron como Fusarium sp.

\subsection{Preselección de aislados como potenciales antagonistas}

Una preselección de bacterias antagonistas de Rhizoctonia solani, fue realizada por (Castillo-Reyes et al., 2015), seleccionando 14 de 80 cepas aisladas. En la caracterización morfológica, todas las cepas presentaron forma de bacilo, tinción de Gram positiva y formación de endospora en la parte central. En este trabajo, de un total de 26 bacterias evaluadas en la preselección (23 aisladas de bioinsumos y 3 de ciego de pollo que sirvieron como controles positivos del género Bacillus) se seleccionaron 6 cepas con posible efecto inhibitorio frente al menos alguno de los 3 fitopatógenos evaluados: Alternaría alternata (I), Fusarium sp. (D) aislado de papa y Fusarium sp. (E) aislado de maní.

En la Tabla 3 se muestran los resultados de la preselección (screen grueso) de aislados con potenciales efectos antagónicos frente a los hongos fitopatógenos, obteniendo como resultado 6 cepas con posible efecto inhibitorio frente al menos alguno de los 3 fitopatógenos evaluados.

Nexo Revista Científica / Vol. 30, No. 02, pp. 96-110 / Diciembre 2017 
Tabla 3. Resultados de las cepas seleccionadas en el ensayo de antagonismo (screen grueso). En el cuadro se muestra el código de la secuencia y código de aislamiento de las bacterias, tipo de muestra del que fueron aislados y su identificación final.

\begin{tabular}{|c|c|c|c|c|c|c|}
\hline \multicolumn{4}{|c|}{ Bacterias } & \multicolumn{3}{|c|}{ Fitopatógenos } \\
\hline $\begin{array}{c}\text { Código } \\
\text { secuencia }\end{array}$ & $\begin{array}{l}\text { Código } \\
\text { aislamiento }\end{array}$ & Tipo Muestra & $\begin{array}{l}\text { Identificación } \\
\text { final }\end{array}$ & $\begin{array}{l}\text { Alternaria } \\
\text { alternata } \\
\text { M5-62N (I) }\end{array}$ & $\begin{array}{l}\text { Fusarium sp. } \\
\text { M1-2-1 (D) }\end{array}$ & $\begin{array}{l}\text { Fusarium sp. } \\
\text { F9 (E) }\end{array}$ \\
\hline $\mathbf{F}$ & DCL4-31 & Bioinsumos & $\begin{array}{l}\text { Bacillus } \\
\text { subtilis }\end{array}$ & + & + & + \\
\hline G & LS6-11 & Bioinsumos & $\begin{array}{l}\text { Bacillus } \\
\text { subtilis }\end{array}$ & + & + & + \\
\hline $\mathbf{P}$ & LS6-211 & Bioinsumos & Bacillus sp. & + & + & + \\
\hline $\mathbf{Q}$ & DCL12-11 & Bioinsumos & Rhizobium sp. & - & + & - \\
\hline $\mathbf{R}$ & $\mathrm{X} 2-10(2) 2$ & Ciego de pollo & Bacillus cereus & + & + & - \\
\hline $\mathbf{S}$ & X5-9CD2 & Ciego de pollo & Bacillus cereus & + & + & - \\
\hline
\end{tabular}

+ Se observó grado de inhibición;

- No se observó ningún grado de inhibición.

3.6 Evaluación del efecto antagónico haciendo énfasis en la búsqueda de B. subtilis

Se evaluó el efecto antagónico de las cepas seleccionadas en el screen grueso, frente a los 5 fitopatógenos Fusarium sp. M1-2-1 (D), Fusarium sp. F15 (E), Alternaría alternata M5-62N (I), Fusarium equiseti M31-1 (J) y Fusarium equiseti F9 (T); obteniendo como resultado que las 6 cepas de bacterias evaluadas presentaron diferentes capacidades para inhibir a distintos fitopatógenos y en algunos casos no se observó efecto inhibitorio. Los resultados del porcentaje de inhibición frente a los fitopatógenos y la tasa de crecimiento micelial de estos se reflejaron en base al promedio de tres repeticiones por tratamiento, estos resultados se muestran en la Figura 5 y la Tabla 4.

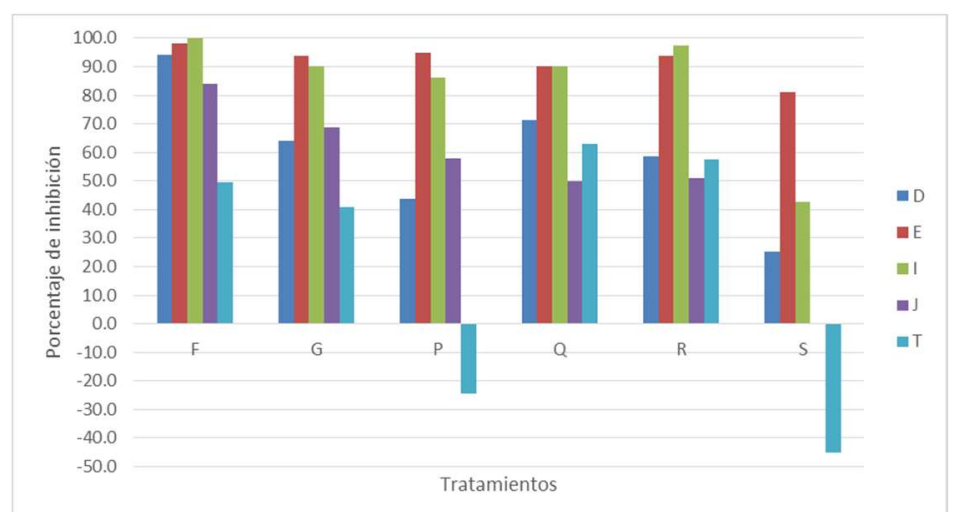

Figura 5. Porcentaje de inhibición del crecimiento de los fitopatógenos: Fusarium sp. M 1-2-1 (D), Fusarium sp. F15 (E), Alternaría alternata M5-62N (I), Fusarium equiseti M 3-1-1 (J) y Fusarium equiseti F9 (T), frente a las Bacterias previamente seleccionadas como inhibidoras de crecimiento: Bacillus subtilis DCL4-31 (F), Bacillus subtilis LS6-11 (G), Bacillus sp LS6-211 (P), Rhizobium sp. DCL12-11 (Q), Bacillus cereus X2-10(2)2 (R) y Bacillus cereus X59CD2 (S). 
Tabla 4. Tasa de crecimiento de fitopatógenos: Fusarium sp. M 1-2-1 (D), Fusarium sp. F15 (E), Alternaría alternata M5-62N (I), Fusarium equiseti M 3-1-1 (J) y Fusarium equiseti F9 (T), en presencia de bacterias seleccionadas como inhibidoras de crecimiento: Bacillus subtilis DCL4-31 (F), Bacillus subtilis LS6-11 (G), Bacillus sp. LS6-211 (P), Rhizobium sp. DCL12-11 (Q), Bacillus cereus X2-10(2)2 (R) y Bacillus cereus X5-9CD2 (S). En la parte inferior de la tabla se muestra el crecimiento de los testigos (sin presencia de bacterias).

\begin{tabular}{cccccc}
\hline \multirow{2}{*}{ Bacterias } & \multicolumn{5}{c}{ Tasa de crecimiento de fitopatógenos (cm/día) } \\
\cline { 2 - 6 } & $\mathrm{D}$ & $\mathrm{E}$ & $\mathrm{I}$ & $\mathrm{J}$ & $\mathrm{T}$ \\
\hline $\mathbf{F}$ & 0.02 & 0.01 & 0.00 & 0.05 & 0.10 \\
\hline $\mathbf{G}$ & 0.13 & 0.03 & 0.04 & 0.10 & 0.12 \\
\hline $\mathbf{P}$ & 0.13 & 0.02 & 0.06 & 0.14 & 0.24 \\
\hline $\mathbf{Q}$ & 0.09 & 0.04 & 0.04 & 0.16 & 0.07 \\
\hline $\mathbf{R}$ & 0.11 & 0.03 & 0.01 & 0.16 & 0.08 \\
\hline $\mathbf{S}$ & 0.20 & 0.08 & 0.24 & 0.33 & 0.28 \\
\hline Tasa de crecimiento de los fitopatógenos sin presencia de bacterias (Testigo) \\
\hline \multicolumn{7}{c}{ Testigo } & Día 13 & Día 10 & Día 10 & Día 13 & Día 14 \\
\hline
\end{tabular}

De manera general, los mejores resultados corresponden al aislado DCL4-31 (F) identificado como Bacillus subtilis, el cual inhibe el crecimiento entre el 83 y el $100 \%$ en cuatro de los cinco hongos fitopatógenos. A pesar de que la cepa LS6-11 (G) también se identificó como B. subtilis no obtuvo los mismos resultados; esto concuerda con lo que refiere (Lagunas-Lagunas et al., 2001) que cepas de una misma especie, pueden exhibir diferentes capacidades para inhibir el crecimiento de diferentes microorganismos. No obstante, las demás cepas evaluadas también inhibieron en cierto grado a alguno de los fitopatógenos. Las cepas LS6211 P y X5-9CD2 S, Bacillus sp. y Bacillus cereus respectivamente, frente al fitopatógeno T (Fusarium equiseti) obtuvieron porcentajes negativos de inhibición -24.52 y $-45.16 \%$, debido a que el hongo creció más rápido en presencia de estas bacterias en comparación a su crecimiento como testigo (Estimulacion). Esto se puede evidenciar con el aumento de la tasa de crecimiento presentado en la Tabla 4, de 0.24 y 0.28 $\mathrm{cm} /$ día, siendo mayor que en el testigo que crecía $0.19 \mathrm{~cm} /$ día.

El efecto protector de los miembros del género Bacillus utilizados en el control de enfermedades fúngicas, puede deberse a la presencia de diferentes mecanismos para antagonizar de forma directa o indirecta el crecimiento de patógenos (Tejera et al., 2012). Varios autores han informado la actividad antagónica del género Bacillus contra diferentes hongos fitopatógenos (Reinoso Pozo et al., 2007), lo que se atribuye a la producción de compuestos de naturaleza peptídica y lipopeptídica como las micobacilinas, iturinas, bacilomicinas, fungistatinas y micosubtilinas (Souto et al., 2004); compuestos que han demostrado ser efectivos en suprimir el crecimiento de patógenos in vitro o in situ (Badía et al., 2011; Sosa et al., 2005; Corrales et al., 2011). Entre los mecanismos de acción implicados en el control biológico están el parasitismo directo y muerte del patógeno, competencia por nutrientes, inducción de resistencia sistémica en la planta, disminuyendo el efecto dañino de los fitopatógenos (Orietta \& Larrea, 2001). Este efecto inhibidor de las especies de Bacillus sobre hongos que causan enfermedades en las plantas puede estar asociado a la producción de enzimas que actúan en la degradación de la pared celular como las quitinasas y proteasas (Rodas et al., 2009).

Los resultados obtenidos evidencian una vez más lo reportado por (Sosa, et al. 2005) sobre el elevado potencial que presentan las bacterias del género Bacillus para el control biológico en condiciones in vitro, ya que está demostrado por numerosos autores que los microorganismos pertenecientes a este género se caracterizan por tener la capacidad de producir sustancias, tales como, metabolitos, antibióticos, enzimas líticas, entre otras que aisladas, purificadas y producidas a gran escala son una valiosa alternativa del control químico, que tanto se ha encarecido a nivel Internacional y del cual existe una tendencia cada vez más

Nexo Revista Científica / Vol. 30, No. 02, pp. 96-110 / Diciembre 2017 


\section{J.M. Méndez-Úbeda et al.}

generalizada a disminuir su uso, debido precisamente a los daños que ha causado al hombre y al medio ambiente.

Un resultado muy interesante que deberá seguirse profundizando en investigaciones futuras, fue el mostrado por la cepa DCL12-11 (Q) identificada como Rhizobium sp., la cual ha sido ampliamente reportada como estimulante cuando se aplica a cultivos de leguminosas (frijol, arveja, garbanzo, lentejas, entre otras) (Hernández et al., 2012), no obstante como se puede apreciar en la Figura 5, también inhibe entre 50-90\% ( $72.8 \%$ en promedio) a determinados fitopatógenos (A. alternata, Fusarium sp. y F. equiseti). Estos resultados coinciden con los reportados por Santillana et al., (2012) en el que cepas de Rhizobium evaluadas mostraron potencial antagónico con A. solani y Fusarium sp., con porcentajes de inhibición hasta de $49 \%$ y de $43 \%$ respectivamente.

Los resultados de estos ensayos indican que es posible considerar que las cepas evaluadas podrían utilizarse como una alternativa en el control biológico de estos hongos fitopatógenos, mediante la aplicación individual o en mezcla para obtener una mayor eficiencia en el control de estos.

\section{CONCLUSIONES}

A partir de cuatro bioinsumos recolectados de diferentes zonas de Nicaragua, se logró obtener 30 aislados, de los cuales 23 corresponden a bacterias, que a través de pruebas morfológicas y moleculares, dos de ellas se identificaron como Bacillus subtilis DCL4-31 (F) y LS6-11 (G). Por otra parte, como producto de la preselección (Screen grueso) de cepas bacterianas antagonistas, se obtuvo 6 cepas con potencial antagónico de 26 evaluadas, estas fueron identificadas como: B. subtilis DCL4-31 (F) y LS6-11 (G), Bacillus sp. LS6211 (P), Rhizobium sp. DCL12-11 (Q), B. cereus X2-10(2)2 (R) y X5-9CD2 (S). El aislado DCL4-31 (F) correspondiente a Bacillus subtilis, fue el que presentó el mejor porcentaje de inhibición con un rango de 50-100\%, pudiéndose considerar como una alternativa en el control biológico de hongos fitopatógenos pertenecientes a los géneros Fusarium y Alternaría. Finalmente, un resultado muy interesante fue el mostrado por la cepa DCL12-11 (Q) identificada como Rhizobium sp., la cual inhibió entre 50-90\% el crecimiento de los fitopatógenos Alternaría alternata, Fusarium sp. y Fusarium equiseti; estos resultados sugieren considerar su aplicación no solo como bioestimulante, sino también como bioprotector al inhibir de crecimiento de ciertos fitopatógenos.

\section{AGRADECIMIENTOS}

A los estudiantes Mario Flores Hernández y Erick Roque Castellano, por el apoyo y dedicación mostrada para realización de este trabajo, al Programa Institucional, Estudios Nacionales y Servicios Ambientales (PIENSA-UNI) por la colaboración como contraparte de este proyecto y a la Universidad Nacional de Ingeniería a través de la Vicerrectoría de Investigación y Desarrollo por haber financiado la realización de esta investigación.

\section{REFERENCIAS}

Álvarez, C., Osorio, N., \& Montoya, M. (2013). Identificación molecular de microorganismos asociados a la rizosfera de plantas de vainilla en Colombia. Acta Biológica Colombiana, 293-305.

Arias, E., \& Piñeros, P. (2008). Aislamiento e identificación de hongos filamentosos de muestras de suelo de los páramos de Guasca y Cruz Verde. Bogotá: Trabajo de Grado. Pontificia Universidad Javeriana.

Badía, M., Hernández, B., Murrel, J., Mahillon, J., \& Peréz, M. (2011). Aislamiento y caracterización de cepas de Bacillus asociadas al cultivo de arroz (Oryza sativa L). Revista Brasileña de Agroecología, 90-99.

Nexo Revista Científica / Vol. 30, No. 02, pp. 96-110 / Diciembre 2017 


\section{J.M. Méndez-Úbeda et al.}

Barquero, L., Campos, S., Tobar, M., Guerrero, A., Sánchez, J., \& Landinez, L. (2007). Informe de vigilancia tecnológica. Bioinsumos. Instituto Colombiano para el Desarrollo de la Ciencia y la Tecnología (COLCIENCIAS). Bogotá, Colombia: Cargraphics.

Benítez, S., Bentley, J., Bustamante, P., Sánchez, C., \& Corrales, L. (2007). Aislamiento de los microorganismos cultivables de la rizosfera de Ornithogalum umbellatum y evaluación del posible efecto biocontrolador en dos patógenos del suelo. NOVA, 147-153.

Carrillo, L. (2003). Alternaría. En Los Hongos de los Alimentos y forrajes (págs. 70-86). Argentina: Universidad Nacional de Salta.

Castillo-Reyes, F., Hernández-Castillo, F., Gallegos-Morales, G., Flores-Olivas, A., Rodríguez-Herrera, R., \& Aguilar, C. (2015). Efectividad in vitro de Bacillus y polifenoles de plantas nativas de México sobre Rhizoctonia-Solani. Revista Mexicana de Ciencias Agrícolas, 549-562.

Chen, K., Yang, J., \& Zhao, H. (2013). Isolation and characterization of a Bacillus strain for alkaline wastewater treatment. African Journal of Microbiology Research. 7 (44): 5119-5125.

Compant, S., Duffy, B., Nowak, J., Clément, C., \& Barka, E. (2005). Use of Plant Growth-Promoting Bacteria for Biocontrol of Plant Diseases: Principles, Mechanisms of Action, and Future Prospects. Appl Environ Microbiol. 71 (9): 4951-4959.

Corrales, L., Sánchez, L., Cuervo, J., Bautista, D., González, L., \& Guevara, M. (2011). Evaluación del efecto biocontrolador de Bacillus spp., frente a Fusarium spp., bajo condiciones de invernadero en Rosmarinus officinalis L. NOVA-Publicación Científica en Ciencias Biomédica. 8 (13): 63-75.

Cuervo Loza, J. (2010). Aislamiento y caracterización de Bacillus spp. como fijadores biológicos de nitrógeno y solubizadores de fosfatos en dos muestras de biofertilizantes comerciales. Bogotá: Tesis de Grado. Pontificia Universidad Javeriana.

Handelsman, J., Raffel, S., Mester, E., Wunderlich, L., \& Grau, C. (1990). Biological Control of DampingOff of Alfalfa Seedlings with Bacillus cereus UW85. Applied and Environmental Microbiology. 56 (3): 713-718.

Hernández, J., Cubillos-Hinojosa, J., \& Milian, P. (2012). Aislamiento de cepas de Rhizobium spp., asociados a dos leguminosas forrajeras en el Centro Biotecnológico del Caribe. Revista Colombiana de Microbiología Tropical. 2 (2): 51-62.

IPSA. (2016). Lista de plagas reportadas en Nicaragua IV versión. Managua: Instituto de Protección y Sanidad Agropecuaria (IPSA).

Jiménez, D. (2007). Caracterización molecular de cepas nativas Colombianas de Azotobacter spp. mediante el análisis de restricción del DNA ribosomal 16S. Trabajo de Grado para optar al título de Microbiólogo Industrial, Pontificia Universidad Javeriana, Bogotá.

Kikot, G. (2012). Caracterización bioquímica, fenotípica y molecular de aislamientos de Fusarium graminearum provenientes de la región pampeana en relación a la patogenicidad. La Plata: Tesis doctoral, Universidad Nacional de La Plata, Facultad de Ciencias Exactas.

Lagunas-Lagunas, J., Zavaleta-Mejía, E., Osada-Kawasoe, S., \& Aranda-Ocampo, S. (2001). Bacillus firmus como Agente de Control Biológico de Phytophthora capsici Leo. en Jitomate (Lycopersicon esculentum Mill.). Revista Mexicana de Fitopatología. 19 (1): 57-65.

Nexo Revista Científica / Vol. 30, No. 02, pp. 96-110 / Diciembre 2017 


\section{J.M. Méndez-Úbeda et al.}

Moreno, J., \& Albarracín, V. (2012). Aislamiento, cultivo e identificación de microorganismos ambientales a partir de muestras naturales. Reduca (Biología). Serie Microbiología, 79-93.

Orberá, T., Serrat, M., \& Ortega, E. (2014). Potencialidades de la cepa SR/B-16 de Bacillus subtilis para el control de enfermedades causadas por hongos en cultivos de interés agrícola. Biotecnología Aplicada. 31: $7-12$.

Orietta, F., \& Larrea, V. (2001). Microorganismos antagonistas para el control fitosanitario. Manejo integrado de plagas (Costa Rica). 62: 96-100.

Páramo, L. (2012). Caracterización de comunidades microbianas con potencial biotecnológico para la prevención del deterioro estructural. . Reynosa, Tamaulipas.: Tesis doctoral. Instituto Politécnico Nacional. Centro de Biotecnología Genómica.

Pérez, R. (2012). Inoculación de bacterias promotoras de crecimiento vegetal en pepino (Cucunis sativus L.). Tesis de maestría, Institución de enseñanza e investigación en ciencias agrícolas, Montecillo, Texcoco. México.

Reinoso Pozo, Y., Casadesús Romero, L., García Suárez, A., Gutiérrez Pérez, J., \& Álvarez-Rivera, V. (2006). Aislamiento, selección e identificación de bacterias del género Bacillus antagonistas de Pectobacterium carotovorum. Fitosanidad. 10 (3): 187-191.

Reinoso Pozo, Y., Vaillant Flores, D., Casadesús Romero, L., García Pérez, E., \& Pazos Álvarez-Rivera, V. (2007). Selección de cepas de Bacillus y otros géneros relacionados para el control biológico de hongos fitopatógenos. Fitosanidad. 11 (1): 35-40.

Rodas, B., Quero, M., Magaña, H., \& Reyes, A. (2009). Selección de cepas nativas con actividad QuitinoProteolítica de Bacillus sp. aisladas de suelos tropicales. Revista Colombiana de Biotecnología. 11 (1): 107113.

Ruiz-Sánchez, E., Mejía-Bautista, M., Cristóbal-Alejo, J., Valencia-Botín, A., \& Reyes-Ramírez, A. (2014). Actividad antagónica de filtrados de Bacillus subtilis contra Colletotrichum gloeosporioides (Penz.). Rev. Mex. Cienc. Agríc. 5 (7): 1325-1332.

Santambrosio, Ortega, \& Garibaldi. (2009). Catedra de Biotecnología. Tinsión y observación de microorganismos. Universidad Tecnológica Nacional, Facultad Regional. Rosario, Argentina. p 1-9.

Santillana, N., Zúñiga, D., \& Arellano, C. (2012). Capacidad promotora del crecimiento en cebada (Hordeum vulgare) y potencial antagónico de Rhizobium leguminosarum y Rhizobium etli. Agrociencia Uruguay. 16 (2): 11-17.

Sosa, A., Pazos, V., \& Torres, D. (2005). Aislamiento y selección de bacterias pertenecientes al género Bacillus con potencialidades para el control biológico en semilleros de tabaco. Centro Agrícola. 32 (3): 25 29.

Souto, G., Correa, O., Montecchia, M., Kerber, N., Pucheu, N., Bachur, M., \& García, A. (2004). Genetic and functional characterization of a Bacillus sp. strain excreting surfactin and antifungal metabolites partially identified as iturin-like compounds. Journal of Applied Microbiology, 1247-1256. 
Tamura, K., Peterson, D., Peterson, N., Stecher, G., Nei, M., \& Kumar, S. (2011). MEGA5: Molecular Evolutionary Genetics Analysis using Maximum Likelihood, Evolutionary Distance, and Maximum Parsimony Methods. Molecular Biology and Evolution 28, 2731-2739.

Tejera, B., Heydrich, M., \& Rojas, M. (2012). Antagonismo de Bacillus spp. frente a hongos fitopatógenos del cultivo del arroz (Oryza sativa L.). Rev. Protección Veg. 27 (2): 117-122.

Tejera-Hernández, B., Rojas-Badía, M., \& Heydrich-Pérez, M. (2011). Potencialidades del género Bacillus en la promoción del crecimiento vegetal y el control biológico de hongos fitopatógenos. Revista CENIC. Ciencias Biológicas. 42 (3): 131-138.

\section{SEMBLANZA DE LOS AUTORES}

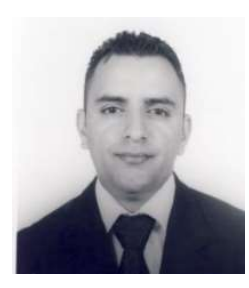

José Mamerto Méndez-Úbeda: Obtuvo el grado de Ingeniero Agrícola en la Universidad Nacional de Ingeniería, Nicaragua, donde actualmente es profesor Encargado de Catedra, investigador acreditado y Coordinador de Investigación de la Facultad de Tecnología de la Construcción. Egresado de la maestría Interinstitucional en Biotecnología, Nicaragua. Tutor de un sinnúmero de monografías de grado en la carrera de Ingeniería Agrícola y ha colaborado en trabajos de Investigación multidisciplinarios en el sector agrícola. Cuenta con diferentes cursos y seminarios de capacitación nacionales e Internacionales en países como México e Israel.

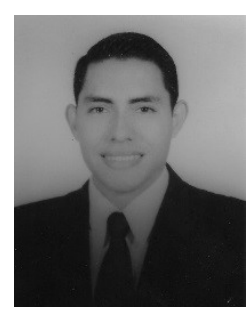

Mario Sergio Flores Hernández, Graduado como Ingeniero Agrícola en la Universidad Nacional de Ingeniería, Nicaragua, en el año 2017. Excelencia académica de la carrera de Ingeniería Agrícola, en los años 2014 y 2015. Proyectista ganador en Feria tecnológica TECNO-UNI edición 2015, en el área de Biotecnología, en colaboración con el Programa de Investigación, Estudios Nacionales y Servicios del Ambiente (PIENSA). Expositor en VII Congreso Nacional de Ingeniería Agrícola, UNI y II Congreso Internacional "Las más recientes innovaciones para enfrentar la variabilidad climática en la producción agropecuaria" del Instituto Nicaragüense de Tecnología Agropecuaria.

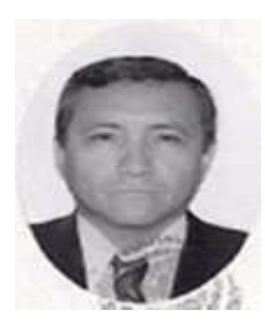

Leandro Alberto Páramo Aguilera, Graduado como Ingeniero Químico con maestría en Ingeniería Química y énfasis en procesos biotecnológicos, en el Instituto Superior Politécnico "José Antonio Echeverría", ISPJAE, de la Ciudad de la Habana, Cuba, en el año 1990. En 1997 se gradúa como Master en Microbiología y énfasis en bacteriología en la Universidad de Costa Rica, UCR. En junio del 2012, se gradúa como Doctor en Ciencias en el área de Biotecnología en el Centro de Biotecnología Genómica (CBG) del Instituto Politécnico Nacional (IPN) de México. Amplia experiencia en el desarrollo de procesos biotecnológicos (biofertilizantes, bebidas alcohólicas, fermentados lácteos, bioprospección, compostaje, etc). 